\title{
Acanthophysium sp. KMF001, a New Strain with High Cellulase Activity ${ }^{1}$
}

\author{
Sae-Min $\mathrm{YOON}^{2} \cdot$ So-Hyun $\mathrm{PARK}^{2} \cdot$ Tea-Jong $\mathrm{KIM}^{2}$ • \\ Young-Kyoon $\mathrm{KIM}^{2} \cdot$ Yeong-Suk KIM(iD ${ }^{2, \dagger}$
}

\begin{abstract}
Cellulase is an eco-friendly biocatalyst, and its demand is growing in many industrial applications such as food, textile, paper, and bioenergy. Strains with a high cellulase activities are the starting point for the economic production of cellulase. In a previous study, Acanthophysium sp. KMF001 with high cellulase production ability was selected among 54 wood-rotting fungi. In this study, we evaluated the cellulase productivity of Acanthophysium sp. KMF001 quantitatively and analyzed its taxonomic location using a genetic method. Acanthophysium sp. KMF001 showed high cellulase productivity similar to that of Acanthophysium bisporum and was much better than A. bisporum in specific enzyme activity. The 28S rRNA sequence of Acanthophysium sp. KMF001 was similar to that of Acanthophysium lividocaeruleum MB1825, with $98.40 \%$ homology. Phylogenetic analysis suggested that Acanthophysium sp. KMF001 is a new strain. In this study, we propose a new strain with high cellulase productivity.
\end{abstract}

Keywords: cellulase, Acanthophysium, new strain, 28S rRNA, phylogenetic

\section{INTRODUCTION}

Cellulose is a biopolymer made of glucose, and it is used as a structural biopolymer that is difficult to break down in ecosystems. Cellulase is a collective enzyme that converts cellulose to glucose with three kinds of cellulase: endo- $\beta$-1,4-glucanase (EG; EC 3.2.1.4), cellobiohydrolase (CBH; EC 3.2.1.74), and $\beta$ -glucosidase (BGL; EC 3.2.1.21) (Goyal et al., 1991; Hong et al., 2001; Li et al., 2006; Kim et al., 2015a). For efficient cellulose degradation, EG, $\mathrm{CBH}$, and BGL degrade cellulose enzymatically in sequence (Ali et al., 2013; Biswas et al., 2011; Gao et al., 2014; Haigler and Weimer, 1991; Howard et al., 2002; Schülein, 1988; Zhu et al., 2009). EG randomly hydrolyzes the amorphous regions of cellulose to produce oligosaccharides of various lengths. $\mathrm{CBH}$ hydrolyzes the end of cellulose oligosaccharide chains produced by EG and produces cellobiose units. Cellobioses produced by $\mathrm{CBH}$ are converted into two glucoses by BGL. The enzymatic efficiency of cellulose is enhanced by the activity and complementary action of enzymes of each type. Many studies showed that wood-rotting fungi degrade cellulose efficiently by the complementary action of cellulase. Therefore, many commercial cellulases are produced from wood-rotting fungi

\footnotetext{
${ }^{1}$ Date Received September 16, 2019, Date Accepted October 31, 2019

2 Department of Forest Products and Biotechnology, Kookmin University, Seoul 02707, Republic of Korea

$\dagger$ Corresponding author: Yeong-Suk KIM (e-mail: yskim@kookmin.ac.kr, ORCID: 0000-0002-0221-5764)
} 
such as Trichoderma viride, Trichoderma koningii, Penicillium pinophilum, Sporotrichum pulverulentum, Fusarium solani, Aspergillus niger, Trichoderma reesei, and Penicillium funiculosum (Castellanos et al., 1995; Fang et al., 2010; Gao et al., 2008; Howard et al., 2002; Jamshidian et al., 2016; Leathers et al., 2015; Lee et al., 2010; Pandey et al., 2006; Smits et al., 1996; Sutivisedsak et al., 2013; Zhang et al., 2012).

Among fungi, T. reesei has already been studied and used extensively in the production of commercial enzymes (Goldbeck et al., 2013; Howard et al., 2002; Jørgensen et al., 2003; Kurabi et al., 2005). Trichoderma has been reported to be suitable for the production of industrial cellulase because its ability to produce extracellular enzymes is greater than that of bacteria (Rosgaard et al., 2006). T. reesei, however, cannot break down lignin (Howard et al., 2002) and the BGL of T. reesei is partially bound to the mycelium, so BGL is not efficiently recovered during enzyme production (Delabona et al., 2012). In the case of Schizophyllum, it was reported that the extracellular polysaccharide schizophyllan is produced during cellulase production (Esterbauer et al., 1991; Jamshidian et al., 2016; Leathers et al., 2015). Schizophyllan increased the viscosity of culture with cellulase production by forming a jelly-like structure. It is difficult to produce highly purified extracellular cellulase because of the high viscosity of enzyme solution by schizophyllan. In general, good microbial strains for economic enzyme production have a high enzymatic activity and a high specific activity without production of impurities in culture medium. In this study, we report Acanthophysium sp. KMF001, which produced cellulase with high activity and high specific activity.

Acanthophysium is a fungus in the Stereaceae family and Basidiomycota phylum and is known to be widespread in nature, but the ecological role of Acanthophysium is still unclear.

\section{MATERIALS and METHODS}

\subsection{Strains used in this study}

Acanthophysium sp. KMF001 (KCTC 18282P) was deposited at Korea Collection for Type Culture (Jeongeup-si, Korea). Acanthophysium bisporum (MUCL 32213), Acanthophysium cerussatum (MUCL 32645), and Acanthophysium lividocaeruleum (MUCL 33688) were purchased from the Belgian Co-ordinated Collections of Micro-organisms (Ottignies-Louvainla-Neuve, Belgium) as comparative strains for cellulase activity.

\subsection{Culture conditions for the production of crude cellulase}

Acanthophysium sp. KMF001 was activated on potato dextrose agar (catalog no. 7349834; BD Biosciences Korea, Seoul, Korea) plates at $30^{\circ} \mathrm{C}$ for 5 to 7 days. A. bisporum, A. cerussatum, and A. lividocaeruleum were activated on malt extract agar $(20 \mathrm{~g} / \mathrm{L}$ malt extract, $20 \mathrm{~g} / \mathrm{L}$ glucose, $1 \mathrm{~g} / \mathrm{L}$ peptone, and $20 \mathrm{~g} / \mathrm{L}$ agar) plates at $25^{\circ} \mathrm{C}$ for 5 to 7 days.

The activated Acanthophysium sp. KMF001 was inoculated in $100 \mathrm{~mL}$ of potato dextrose broth (catalog no. 8129687; BD Biosciences Korea) and incubated at $30^{\circ} \mathrm{C}$ for 5 days under the shaking condition at 150 rpm to make a pre-culture. For A. bisporum, $A$. cerussatum, and A. lividocaeruleum, the activated cells were inoculated in $50 \mathrm{~mL}$ of malt extract broth (catalog no. 218630; BD Biosciences Korea) and incubated at $25^{\circ} \mathrm{C}$ for 5 days under the shaking condition at 150 rpm to make a pre-culture.

In the main culture, all four strains were inoculated with $5 \%(\mathrm{v} / \mathrm{v})$ pre-culture in $200 \mathrm{~mL}$ modified TYE medium with cellulose $[7 \mathrm{~g} / \mathrm{L}$ tryptone, $3 \mathrm{~g} / \mathrm{L}$ yeast extract, $5 \mathrm{~g} / \mathrm{L} \mathrm{K}_{2} \mathrm{HPO}_{4}, 5 \mathrm{~g} / \mathrm{L} \mathrm{KH}_{2} \mathrm{PO}_{4}, 3 \mathrm{~g} / \mathrm{L} \mathrm{MgSO}_{4}$. $7 \mathrm{H}_{2} \mathrm{O}$, and $20 \mathrm{~g} / \mathrm{L}$ cellulose $(20-100 \mathrm{~mm}$; catalog no.25384405; Daejung, Seoul, Korea) at $\mathrm{pH}$ 6.0] in 
a $1 \mathrm{~L}$ baffled flask and incubated for 3 weeks under the shaking condition at $150 \mathrm{rpm}$ at $30^{\circ} \mathrm{C}$ for Acanthophysium sp. KMF001 and at $25^{\circ} \mathrm{C}$ for $A$. bisporum, A. cerussatum, and A. lividocaeruleum.

\subsection{Cellulase production}

The crude supernatant from each culture was collected, cells were removed by filtration using Whatman filter paper No. 1 (catalog no. 1001-110; GE Healthcare Life Sciences, Seoul, Korea). The cell free supernatant of each was analyzed on the cellulase activity.

\subsection{Measuring enzymatic activity of cellulase}

For the EG activity assay, $5 \mu \mathrm{L}$ of crude enzyme solution was mixed with $45 \mu \mathrm{L}$ of substrate solution made with $2 \%(\mathrm{w} / \mathrm{v})$ carboxylmethylcellulose sodium salt (catalog no. MKBW6753V; Sigma-Aldrich Korea LLC, Yongin, Korea) in $0.1 \mathrm{M}$ sodium citrate buffer at $\mathrm{pH}$ 4.5. The mixture was incubated at $50^{\circ} \mathrm{C}$ for 30 minutes. The reaction was stopped by adding $50 \mu \mathrm{L}$ of copper solution and heating at $100^{\circ} \mathrm{C}$ for 10 minutes. The amount of produced reducing end by EG was measured using the Somogyi-Nelson method (Nelson, 1944). One unit of EG was defined as the amount of enzyme producing $1 \mu \mathrm{mol}$ glucose for 30 minutes under the described reaction condition.

For the CBH activity assay, $100 \mu \mathrm{L}$ of crude enzyme solution was mixed with $100 \mu \mathrm{L}$ of $10 \mathrm{mM} p$ nitrophenyl- $\beta$-D-cellobioside (catalog no. 077M4023V; Sigma-Aldrich Korea LLC) and $800 \mu \mathrm{L}$ of $0.1 \mathrm{M}$ sodium citrate buffer at $\mathrm{pH}$ 4.5. The mixture was incubated at $50^{\circ} \mathrm{C}$ for 15 minutes. The reaction was stopped by adding $100 \mu \mathrm{L}$ of $2 \mathrm{M} \mathrm{Na}_{2} \mathrm{CO}_{3}$. The amount of produced p-nitrophenol by $\mathrm{CBH}$ was measured at $405 \mathrm{~nm}$ using a Opsys MR microplate reader (Hynex Technologies, Chantilly, VA, USA). One unit of $\mathrm{CBH}$ was defined as the amount of enzyme producing $1 \mu$ mol $p$ nitrophenol for 15 minutes under the described reaction condition.

For the BGL activity assay, all measuring procedure was similar with the above $\mathrm{CBH}$ activity assay with switching the substrate to $10 \mathrm{mM}$ p-nitrophenyl- $\beta$-Dglycopyranoside (catalog no. BCBP2339V; SigmaAldrich Korea LLC). Enzymatic activity was defined as the enzyme activity of the crude solution based on the volume and expressed in $\mathrm{U} / \mathrm{mL}$.

\subsection{Measuring specific activity of cellulase}

To calculate a specific activity of each cellulase, the protein concentration was measured using the Bradford's methods with bovine serum albumin as a standard (Bradford, 1976). Enzyme with $400 \mu \mathrm{L}$ and protein assay reagent with $100 \mu \mathrm{L}$ (Bio-Rad Laboratories, Inc., Hercules, CA, USA) were mixed violently in tubes for 10 seconds. The absorbance was measured at $595 \mathrm{~nm}$ after 5-minute incubation in room temperature. The specific activity of enzymes was defined as the cellulase activity per milligram of total protein and expressed in $\mathrm{U} / \mathrm{mg}$.

\subsection{Genetic analysis of Acanthophysium sp. KMF001}

Cells of Acanthophysium sp. KMF001 from the main culture were disrupted with TissueLyser LT (Qiagen Korea Ltd., Seoul, Korea), and the genomic DNA was purified using the DNeasy Plant Mini kit (Qiagen Korea Ltd.). The internal transcribed spacer region of $28 \mathrm{~S}$ rRNA was amplified using polymerase chain reaction (PCR) with two primers: ITS4 (5'-TCCTCCGCTTA TTGATATGC-3') and ITS5 (5'-GGAAGTAAAAGT CGTAACAAGG-3'). The PCR condition with 35 cycles was $95^{\circ} \mathrm{C}$ for 20 seconds for denaturation, $55^{\circ} \mathrm{C}$ for 4 seconds for annealing, and $72^{\circ} \mathrm{C}$ for 60 seconds for 
extension. The amplified DNA was sequenced by Biofact Co., Ltd. (Daejeon, Korea). The analyzed sequence was registered at GenBank at the National Center for Biotechnology Information (NCBI; https:// www.ncbi.nlm.nih.gov/) under MM680758.

The homologous sequences in the nucleotide database were identified using Nucleotide BLAST (https:// blast.ncbi.nlm.nih.gov/Blast.cgi). They were aligned, and phylogenetic trees were analyzed using MEGA4 software (Tamura et al., 2007). The corresponding ribosomal DNA region of each strain was used for making phylogenetic trees with the distance methods based on the similarity.

\section{RESULTS and DISCUSSION}

\subsection{Cellulase activity of Acanthophysium spp.}

Acanthophysium sp. KMF001 was selected among 54 wood-rotting fungi based on the cellulase activity (Kim et al., 2015b). To evaluate the cellulase activity of Acanthophysium sp. KMF001, we purchased three Acanthophysium strains, namely, A. bisporum, A. cerussatum, and $A$. lividocaeruleum, and the cellulase activities of all four strains, including Acanthophysium sp. KMF001, were analyzed (Fig. 1). Cellulase production was analyzed on the basis of culture medium volume (Fig. 1A, 1C, and 1E) and protein weight for the specific activity (Fig 1B, 1D, and 1F). As shown in Fig. 1, A. cerussatum and A. lividocaeruleum showed low enzymatic and specific activity of cellulase, and Acanthophysium sp. KMF001 and A. bisporum showed strong cellulase activity among the four tested strains.

The EG activity of Acanthophysium sp. KMF001 showed the highest enzymatic activity at $94.54 \mathrm{U} / \mathrm{mL}$ on 15 days of cultivation and similar enzyme activity until 21 day. On the other hand, EG enzyme activity of $A$. bisporum showed a similar level of EG activity to Acanthophysium sp. KMF001 at 15 days of cultivation, but the enzyme activity decreased with further incubation time after that (Fig. 1A). However, the specific activities of EG in Acanthophysium sp. KMF001 and A. bisporum showed $245 \mathrm{U} / \mathrm{mg}$ and 165 $\mathrm{U} / \mathrm{mg}$, respectively, at the 15 days of cultivation (Fig. 1B). These results indicated that the enzyme productivity per unit volume of the culture was similar in both strains, but the cellulase content based in the protein released to the outside of the cell in Acanthophysium sp. KMF001 was 1.5 times higher than that in A. bisporum. The other two cellulase enzyme activities, namely, CBH (Fig. 1D) and BGL (Fig. 1F), showed similar differences in specific enzyme activities. The production of such high-purity cellulase is advantageous for enzyme production and application.

The CBH activities on the 15th day of cultivation with Acanthophysium sp. KMF001 and A. bisporum showed $6.83 \mathrm{U} / \mathrm{mL}$ and $7.19 \mathrm{U} / \mathrm{mL}$, respectively (Fig. 1C). The BGL activities on the 18th day of cultivation in Acanthophysium sp. KMF001 and A. bisporum showed $63.20 \mathrm{U} / \mathrm{mL}$ and $57.46 \mathrm{U} / \mathrm{mL}$, respectively (Fig. 1E). The specific activity of $\mathrm{CBH}$ and $\mathrm{BGL}$ in Acanthophysium sp. KMF001 was higher, with 17\% and $28 \%$ more, respectively, than those in A. bisporum (Fig. 1D and 1F, respectively). In particular, on the 15th day of cultivation, the specific $\mathrm{CBH}$ activity in Acanthophysium sp. KMF001 was about double of that in A. bisporum (Fig. 1D), and the specific BGL activity in Acanthophysium sp. KMF001 on the 12th day of cultivation was also about double of that in A. bisporum (Fig. 1F). In the case of Acanthophysium sp. KMF001, the decrease in $\mathrm{CBH}$ activity was moderate after the 15th day of cultivation, but the $\mathrm{CBH}$ activity of $A$. bisporum rapidly decreased during the same incubation time.

On the basis of the above results, all enzymatic cellulase activities of Acanthophysium sp. KMF001 were similar to that of $A$. bisporum, but the specific 
A.

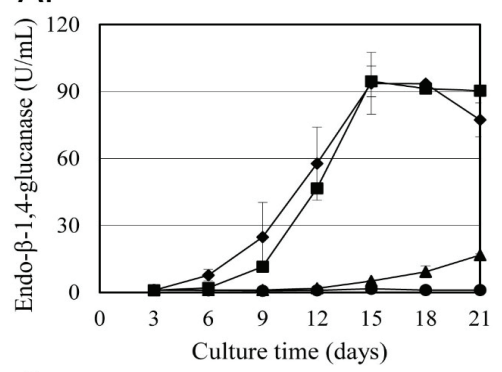

C.

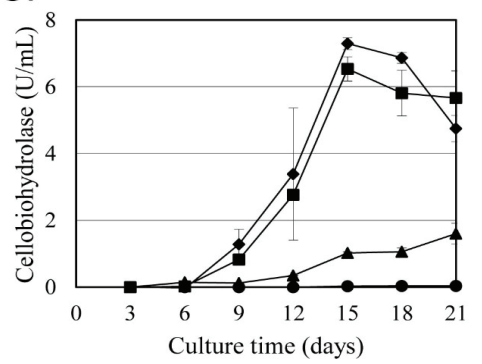

E.

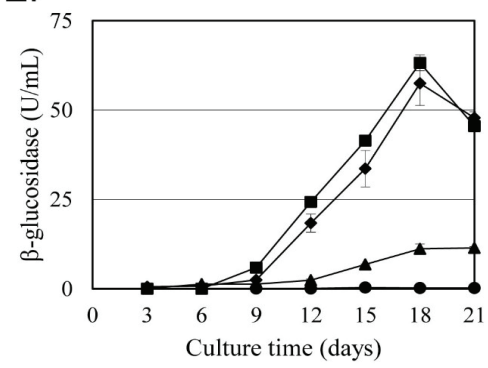

B.

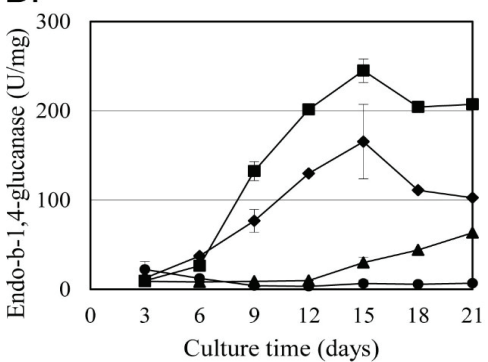

D.

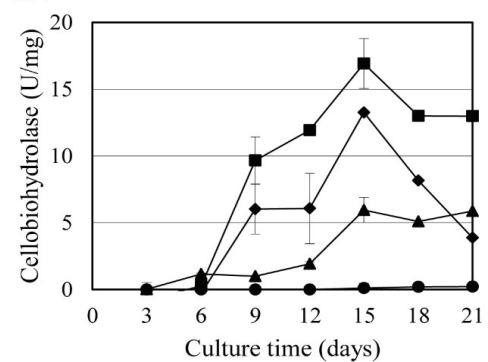

F.

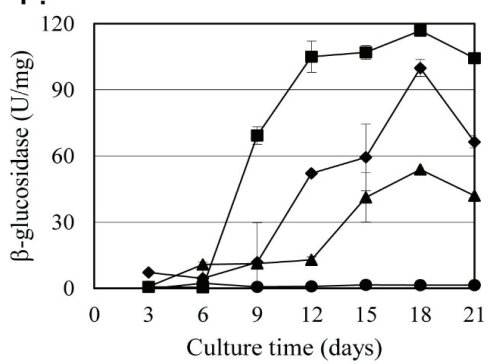

Fig. 1. Cellulase activity of four strains: Acanthophysium sp. KMF001 (ロ), A. bisporum ( $\bullet$ ), A. cerussatum $(\boldsymbol{\Lambda})$, and A. lividocaeruleum (•). (A and B) EG activity, (C and D) CBH activity, and (E and F) BGL activity. (A, C, and E) Enzymatic activity in the crude solution based on the culture volume and (B, D, and F) specific activity of the enzyme based on the protein weight. The values are the average of three replicates. The standard deviations are shown.

activity of Acanthophysium sp. KMF001 showed significantly higher levels of all tested enzyme activities than A. bisporum. This observation suggested that Acanthophysium sp. KMF001 was better than the others in Acanthophysium spp. tested in this study for high cellulase production. In a previous study, the $\mathrm{CBH}$ and BGL activities of Acanthophysium sp. KMF001 were higher than it of Trichoderma reesei, Fomitopsis palustris, and Aspergillus niger (Kim et al., 2015b).
Considering the enzyme activities in the culture solution and specific activities in this study, the 15th day of cultivation is ideal for cellulase production of Acanthophysium sp. KMF001. In a previous study, the crude cellulase of Acanthophysium sp. KMF001 improved the quality of fabric effectively (Shin et al., 2016). In addition to effective cellulase production, Acanthophysium sp. KMF001 produced a novel endo- $\beta$ -1,4-xylanase, which was an enzyme for hemicellulose 
Sae-Min YOON $\cdot$ So-Hyun PARK $\cdot$ Tea-Jong KIM $\cdot$ Young-Kyoon KIM • Yeong-Suk KIM

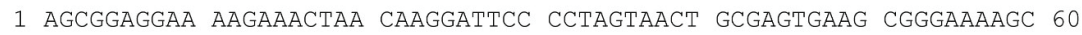

61 TCAAATTTAA AATCTgGCGg CCTCTGgTCG TCCGAgTtgT AgTCTgGAgA AgCGTTTTCC 120

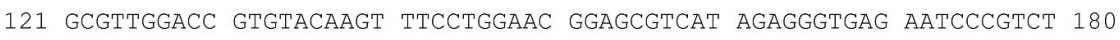

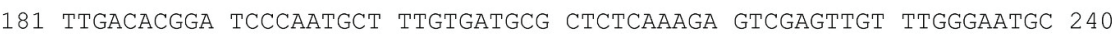

241 AgCTCAAAAT GgGtgGtgAA TTCCATCtAA AgCTAAAtAT TGgCGAgAgA CCGATAgCGA 300

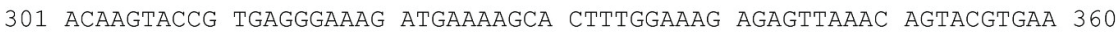

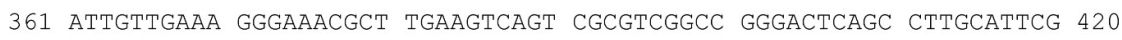

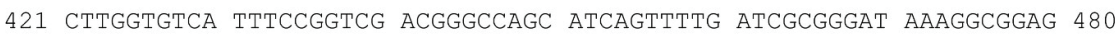

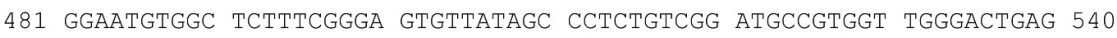

541 GAACTCAgCA CGCCTTtATg GCCGgGgtTC GCCCACGTAC CTGCTTAggA TgCtgGCGTA 600

601 ATGGCTTTAA ACGACCCGTC TTGA
\end{abstract}

Fig. 2. Base sequence of $28 \mathrm{~S}$ rRNA in Acanthophysium sp. KMF001. This sequence was registered at GenBank at the NCBI under MM680758.

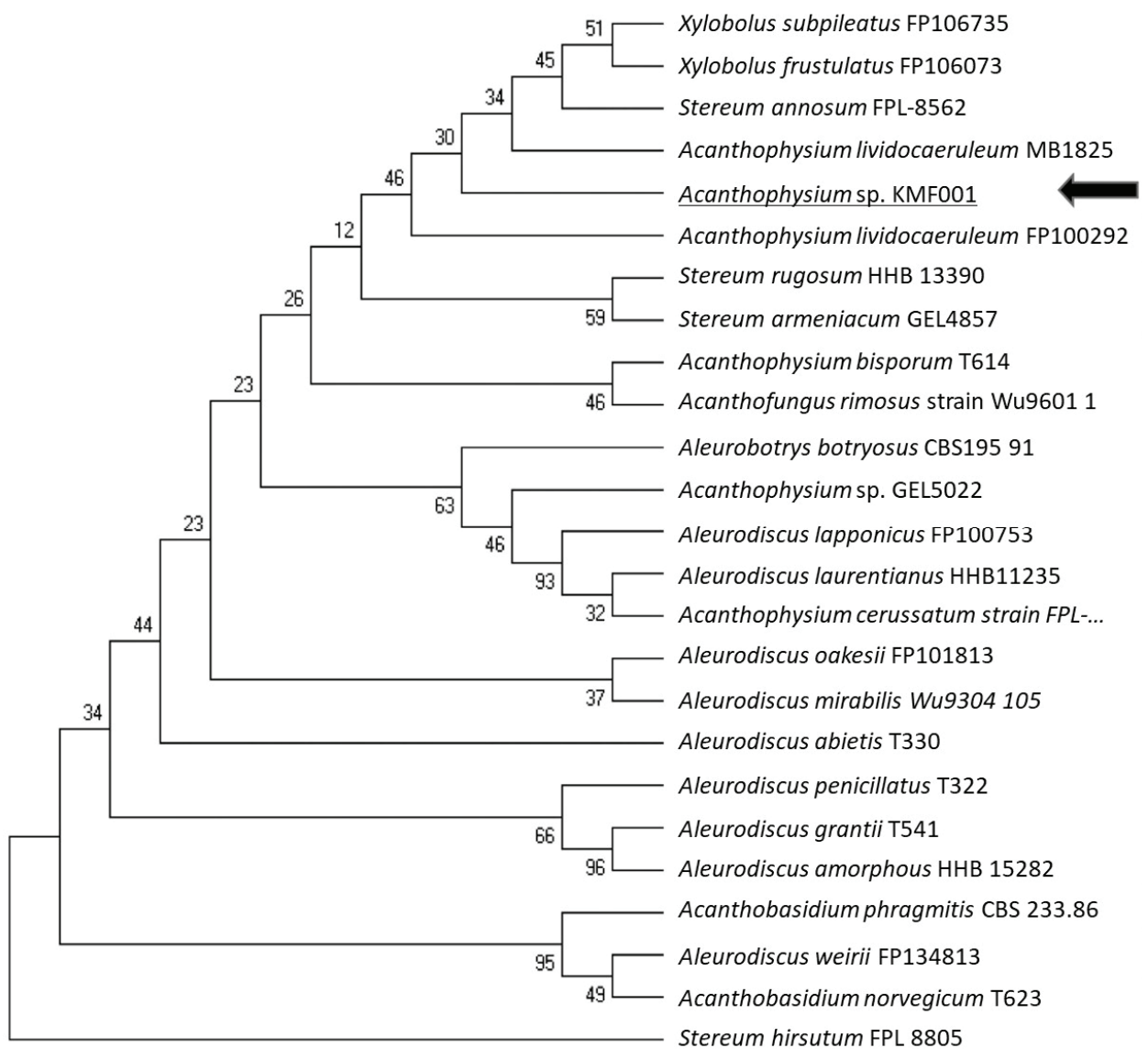

Fig. 3. Phylogenetic trees of Acanthophysium sp. KMF001 with other related fungal species. 
Acanthophysium sp. KMF001, a New Strain with High Cellulase Activity

Table 1. Homology search by the NCBI, Acanthophysium sp. KMF001

\begin{tabular}{clccc}
\hline Accession number & \multicolumn{1}{c}{ Description } & Query coverage (\%) & Expect value & Identity (\%) \\
\hline \hline AY039314 & A. lividocaeruleum MB1825 & 100 & 0.0 & 98.40 \\
AF506400 & A. lividocoeruleum & 100 & 0.0 & 98.24 \\
MH877876 & Xylobolus subpileatus CBS 126032 & 100 & 0.0 & 97.92 \\
MH866478 & Xylobolus frustulatus CBS 271.28 & 100 & 0.0 & 97.92 \\
KX066002 & X. subpileatus FP102567 & 100 & 0.0 & 97.92 \\
AF506491 & X. frustulatus KGN980928 & 100 & 0.0 & 97.92 \\
AY039319 & A. lividocaeruleum FP100292 & 100 & 0.0 & 97.92 \\
AY039307 & X. frustulatus FP106073 & 100 & 0.0 & 97.92 \\
MH867100 & X. subpileatus CBS 415.34 & 100 & 0.0 & 97.76 \\
AY039309 & X. subpileatus FP106735 & 99 & 0.0 & 97.91 \\
AB733325 & Stereum hirsutum NBRC 6520 & 100 & 0.0 & 97.60 \\
AY039310 & A. cerussatum HHB11294 & 100 & 0.0 & 97.60 \\
AF042563 & Unidentified basidiomycete & 100 & 0.0 & 97.60 \\
AY293189 & Hypsizygus tessulatus & 100 & 0.0 & 97.60 \\
\hline
\end{tabular}

degradation (Yoon et al., 2018). All studies suggested that Acanthophysium sp. KMF001 was a good enzymeproducing fungus for decaying wood.

\subsection{Genetic identification of Acanthophysium sp. KMF001}

To identify Acanthophysium sp. KMF001 genetically, the genetic information of its 28S rRNA was analyzed (Fig. 2). The results of the BLAST search with the 28S rRNA nucleotide sequence of Acanthophysium sp. KMF001 using the NCBI nucleotide database are shown in Table 1. The most homologous strain was $A$. lividocaeruleum MB1825, with $98.40 \%$ identity. The next most homologous strains were Acanthophysellum lividocoeruleum, with $98.24 \%$ identity, and additional six strains with $97.92 \%$ identity (Table 1). Using phylogenetic analysis with strains in Table 1, the taxonomic position of Acanthophysium sp. KMF001 was analyzed in Fig. 3. The phylogenetic tree analysis revealed that Acanthophysium sp. KMF001 separated into different phylogenetic branches from $A$. lividocaeruleum MB1825, the most similar strain with 99\% identity by Nucleotide BLAST search. Although Acanthophysium sp. KMF001 was similar to the previously reported A. lividocaeruleum MB1825 with an identity of $98.40 \%$, the phylogenetic analysis suggested that Acanthophysium sp. KMF001 might be a new strain.

\section{CONCLUSION}

Comparison of the enzyme activity with other strains of Acanthophysium genus showed that Acanthophysium sp. KMF001 had similar levels of cellulase activity with $A$. bisporum in all three types, namely, $\mathrm{EG}, \mathrm{CBH}$, and BGL, but the specific enzyme activity of Acanthophysium sp. KMF001 was higher than cellulase from other tested Acanthophysium strains. Although Acanthophysium sp. KMF001 showed 98.40\% nucleotide identity with the most homologous strain, the phylogenetic tree suggested that Acanthophysium 
sp. KMF001 is a new strain by separating into a different phylogenetic branch from the most homologous strain. This study suggested that Acanthophysium sp. KMF001 is a novel bacterium that produces an effective cellulase for the wood decay.

\section{ACKNOWLEDGMENT}

This study was carried out with the support of the "R\&D Program for Forest Science Technology (Project No. 2013070E10-1819-AA03)” provided by the Korea Forest Service (Korea Forestry Promotion Institute).

\section{REFERENCES}

Ali, S.R., Muthuvelayudham, R., Viruthagiri, T. 2013. Enhanced production of cellulase from tapioca stem using response surface methodology. Innovative Romanian Food Biotechnology 12(March): 40-51.

Biswas, A.K., Umeki, K., Yang, W., Blasiak, W. 2011. Change of pyrolysis characteristics and structure of woody biomass due to steam explosion pretreatment. Fuel Processing Technology 92(10): 1849-1854.

Bradford, M.M. 1976. A rapid and sensitive method for the quantitation of microgram quantities of protein utilizing the principle of protein-dye binding. Analytical Biochemistry 72(1-2): 248-254.

Castellanos, O.F., Sinitsyn, A.P., Vlasenko, E.Y. 1995. Comparative evaluation of hydrolytic efficiency toward microcrystalline cellulose of Penicillium and Trichoderma cellulases. Bioresource Technology 52(2): 119-124.

Delabona, P.d.S., Farinas, C.S., da Silva, M.R., Azzoni, S.F., Pradella, J.G.d.C. 2012. Use of a new Trichoderma harzianum strain isolated from the Amazon rainforest with pretreated sugar cane bagasse for on-site cellulase production. Bioresource
Technology 107: 517-521.

Esterbauer, H., Steiner, W., Labudova, I., Hermann, A., Hayn, M. 1991. Production of Trichoderma cellulase in laboratory and pilot scale. Bioresource Technology 36(1): 51-65.

Fang, H., Zhao, C., Song, X.-Y. 2010. Optimization of enzymatic hydrolysis of steam-exploded corn stover by two approaches: Response surface methodology or using cellulase from mixed cultures of Trichoderma reeseiRUT-C30 and Aspergillus niger NL02. Bioresource Technology 101(11): 4111-4119.

Gao, D., Haarmeyer, C., Balan, V., Whitehead, T.A., Dale, B.E., Chundawat, S.P.S. 2014. Lignin triggers irreversible cellulase loss during pretreated lignocellulosic biomass saccharification. Biotechnology for Biofuels 7(1): 175.

Gao, J., Weng, H., Zhu, D., Yuan, M., Guan, F., Xi, Y. 2008. Production and characterization of cellulolytic enzymes from the thermoacidophilic fungal Aspergillus terreus M11 under solid-state cultivation of corn stover. Bioresource Technology 99(16): 7623-7629.

Goldbeck, R., Ramos, M.M., Pereira, G.A.G., MaugeriFilho, F. 2013. Cellulase production from a new strain Acremonium strictumisolated from the Brazilian biome using different substrates. Bioresource Technology 128: 797-803.

Goyal, A., Ghosh, B., Eveleigh, D. 1991. Characteristics of fungal cellulases. Bioresource Technology 36(1): $37-50$.

Haigler, C.H., Weimer, P.J. 1991. Biosynthesis and biodegradation of cellulose. Marcel Dekker New York.

Hong, J., Tamaki, H., Akiba, S., Yamamoto, K., Kumagai, H. 2001. Cloning of a gene encoding a highly stable endo-â-1, 4-glucanase from Aspergillus nigerand its expression in yeast. Journal of Bioscience and Bioengineering 92(5): 434-441. 
Howard, R., Abotsi, E., Jansen van Rensburg, E. 2002. Lignocellulose biotechnology: Issues of bioconversion and enzyme production. African Journal of Biotechnology 2(12): 602-619.

Jørgensen, H., Eriksson, T., Börjesson, J., Tjerneld, F., Olsson, L. 2003. Purification and characterization of five cellulases and one xylanase from Penicillium brasilianum IBT 20888. Enzyme and Microbial Technology 32(7): 851-861.

Jamshidian, H., Shojaosadati, S.A., Vilaplana, F., Mousavi, S.M., Soudi, M.R. 2016. Characterization and optimization of schizophyllan production from date syrup. International Journal of Biological Macromolecules 92: 484-493.

Kim, J.Y., Yoon, S.M., Kim, Y.S. 2015a. Cellulase Activity of Symbiotic Bacteria from Snails, Achatina fulica. Journal of the Korean Wood Science and Technology 43(5): 628-640.

Kim, Y.S., Kim, T.J., Shin, K., Yoon, S.M. 2015b. Novel Acanthophysiumsp. KMF001 having high cellulase activity. US patent Application number: 14/930585.

Kurabi, A., Berlin, A., Gilkes, N., Kilburn, D., Bura, R., Robinson, J., Markov, A., Skomarovsky, A., Gusakov, A., Okunev, O., Sinitsyn, A., Gregg, D., Xie, D., Saddler, J. 2005. Enzymatic hydrolysis of steam-exploded and ethanol organosolv-pretreated douglas-fir by novel and commercial fungal cellulases. Applied Biochemistry and Biotechnology 121(1): 219-230.

Leathers, T.D., Sutivisedsak, N., Nunnally, M.S., Price, N.P.J., Stanley, A.M. 2015. Enzymatic modification of schizophyllan. Biotechnology Letters 37(3): 673-678.

Lee, B.-H., Kim, B.-K., Lee, Y.-J., Chung, C.-H., Lee, J.-W. 2010. Industrial scale of optimization for the production of carboxymethylcellulase from rice bran by a marine bacterium, Bacillus subtilis subsp. subtilis A-53. Enzyme and Microbial Technology 46(1): $38-42$.
Li, Y.-H., Ding, M., Wang, J., Xu, G.-j., Zhao, F. 2006. A novel thermoacidophilic endoglucanase, BaEGA, from a new cellulose-degrading bacterium, Bacillus sp. AC-1. Applied Microbiology and Biotechnology 70(4): 430-436.

Nelson, N. 1944. A photometric adaptation of the Somogyi method for the determination of glucose. Journal of Biological Chemistry 153(2): 375-380.

Pandey, A., Webb, C., FERNANDES, M., Larroche, C. 2006. Enzyme Technology. Springer-Verlag New York Inc., New York.

Rosgaard, L., Pedersen, S., Cherry, J.R., Harris, P., Meyer, A.S. 2006. Efficiency of new fungal cellulase systems in boosting enzymatic degradation of barley straw lignocellulose. Biotechnology Progress 22(2): 493-498.

Schülein, M. 1988. Cellulases of Trichoderma reesei, Methods in Enzymology (vol. 160. pp. 234-242), Academic Press.

Shin, K., Yoon, S.-M., Kim, J.H., Kim, Y.-K., Kim, T.-J., Kim, Y.-S. 2016. Biopolishing of cotton fabric using crude cellulases from Acanthophysium sp. KMF001. Journal of the Korean Wood Science and Technology 44(3): 381-388.

Smits, J.P., Rinzema, A., Tramper, J., Sonsbeek, H.M.V., Knol, W. 1996. Solid-state fermentation of wheat bran by Trichoderma reesei QM9414: substrate composition changes, C balance, enzyme production, growth and kinetics. Applied Microbiology and Biotechnology 46(5): 489-496.

Sutivisedsak, N., Leathers, T.D., Bischoff, K.M., Nunnally, M.S., Peterson, S.W. 2013. Novel sources of â-glucanase for the enzymatic degradation of schizophyllan. Enzyme and Microbial Technology 52(3): 203-210.

Tamura, K., Dudley, J., Nei, M., Kumar, S. 2007. MEGA4: molecular evolutionary genetics analysis (MEGA) software version 4.0. Molecular Biology and Evolution 24(8): 1596-1599. 
Yoon, S.-M., Kim, Y.-S., Kim, Y.-K., Kim, T.-J. 2018. A novel endo-â-1,4-xylanase from Acanthophysium sp. KMF001, a wood rotting fungus. Journal of the Korean Wood Science and Technology 46(6): 670-680.

Zhang, H., Sang, Q., Zhang, W. 2012. Statistical optimization of cellulases production by Aspergillus nigerHQ-1 in solid-state fermentation and partial enzymatic characterization of cellulases on hydrolyzing chitosan. Annals of Microbiology 62(2): 629-645.

Zhu, J.Y., Pan, X.J., Wang, G.S., Gleisner, R. 2009. Sulfite pretreatment (SPORL) for robust enzymatic saccharification of spruce and red pine. Bioresource Technology 100(8): 2411-2418. 